\title{
Usage of digital learning object about breast cancer in primary health care
}

\author{
Denise Tolfo Silveira, Agnes Ludwig Neutzling, Tamyres Oliveira dos Santos, Stephani Catherini \\ Paz Brondani \\ School of Nursing, Rio Grande do Sul Federal University, Brazil \\ Correspondence: Denise Tolfo Silveira. Address: Rua São Manoel, 963, Rio Branco, CEP 90620-110 - Porto Alegre, RS - \\ Brazil. E-mail: dtolfo@enf.ufrgs.br.
}

Received: May 23, 2012

Accepted: November 29, 2012

Online Published: December 25, 2012

DOI : $10.5430 /$ jnep.v3n5p149

URL: http://dx.doi.org/10.5430/jnep.v3n5p149

\begin{abstract}
This was a study to evaluate the digital learning object about breast cancer in primary health care. This is a cross-sectional study non-compared, executed at a Health center in the south of Brazil with 16 members of a climacteric group. The population of study shows an average of 63 years old. An adapted and structured questionnaire was applied and also a focus group interview with a focus. Firstly, the members were enabled to use the computer, then it was applied and evaluated the learning object. In the found results, there was agreement scores between 8.5 and 10 for content, usability and didactic, which was considered satisfactory. The results of the interview were categorized in "use of computer", "information access", "material about breast cancer"; the group declared: satisfied with the object, interested about "breast cancer" and motivated to self-care. It was concluded that this software can be a tool for practice of health professionals, and obtained higher goals, when the proposed was exchange the knowledge, health promotion, digital inclusion and the ways to use the health informatics.
\end{abstract}

\section{Key words}

Women's health, Breast neoplasms, Climacteric, Group processes, Nursing informatics, Public health informatics, Educational technology and problem-based learning

\section{I ntroduction}

One of the priorities of public health policies, of the Unified Health System in Brazil are breast and cervical uterine cancers, Health Promotion and primary attention ${ }^{[1]}$. In Brazilian women the incidence of breast cancer is 49 events/ 100.000 women, with larger incidence on the south of the country (65 events/100.000 women) ${ }^{[2]}$.

The breast cancer, generally, is the most scaring for women ${ }^{[3]}$, the chance to develop the illness increases progressively after the 35 years old4. It is considered climacteric the period that begins after 35 years of age and lasts until 65, when a woman is defined as elderly ${ }^{[5]}$. Accordingly, the females on climacteric period have to pay more attention at the symptoms, in order to detect the breast cancer ${ }^{[5]}$ as early as possible, and need look further into themselves care of breast in order to create opportunities for early detection of cancer. 
The Brazilian health department recommends that the professionals have to promote the physical examination of breast through educative actions with orientation about self-palpation as strategy of self-care ${ }^{[4]}$. The nurse based on the actual and available bibliography, should follow those recommendations, practicing competences in the assistance, teach and research areas. Also, being the subject of breast cancer in the essential actions that refer to primary care, nurses can use innovative measures and alternative methods that captivate your public target.

Thinking about that problem, in 2009, the Federal University of Rio Grande do Sul (UFRGS), with the board of Virtual Teaching Laboratory - Nursing (Levi-Enf), developed a digital learning object about breast cancer (see Figure 1). It has the main topics: “The cancer”, “Epidemiology”, “Treatment”, “Exams”, "Early detection”.

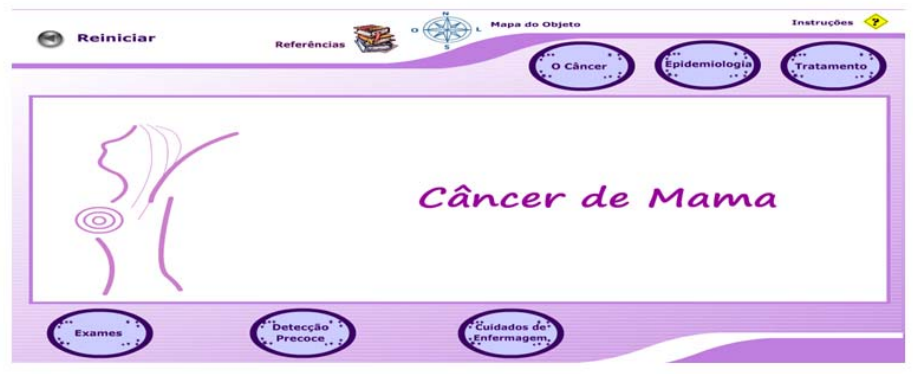

Figure 1. Main menu of learning object about breast cancer

Learning objects are instruments, mostly digitals, which can be used a lot of times, can be showed in different medias (videos, graphics, images), supporting the learning ${ }^{[6]}$. To produce the object about breast cancer in this review, the Problem-Based Learning (PBL) didactic was used to problematize what happens daily, from hypothesis to integration with theory. The Adobe Flash CS4 and Adobe Fireworks CS4 were softwares resources were used to develop this object.

Increasingly the professionals move towards new formats of health services, with the introduction of health informatics ${ }^{[7]}$. The learning object about breast cancer was adapted to the reality of the users of the health center, aiming to get the evaluation about three aspects: content, usability and didactic.

Young people today are born embedded in a digital world, which adults and the elderly seek to adapt to it and the elderly, however, these people are usually away from new technologies ${ }^{[8]}$. Thus, this questions: "why don't the evaluate a digital learning object about breast cancer in the context of a very basic network of users on content, usability and didactic material?", "Why do not bring in the computer a problem that has affected a large percentage of Brazilian women (breast cancer) and hear what these women have to say about the subject?", "bringing the matter 'breast cancer' to the debate from different health technologies become, would be attractive to users of this theme the primary care network? "How would feel these women learning how to use the computer?"

The authors of this review intended to evaluate this kind of educative material with users of primary health care, analyzing their evaluation and perceptions, trying to stimulate the self care and health promotion, as well as the digital inclusion. Beyond that, this research brings up the discussions of the practice of health education with the computer, few implemented with the users of the Unified Health System in Brazil.

\section{Subjects and methods}

This is a cross-sectional study non-compared ${ }^{[9]}$. The qualitative data gave subsidies to analyze the quantitative results, from information collected in group interview with the participants of the review. The study happened on a Health Center 
in the south of Brazil with 16 members of a climacteric group existed for 16 years, which is coordinated by a nurse, once for week. The participants of this group were the target of this study.

To collect the data, was needed a stage to enable of the participants to use the computer, followed to the application and evaluation of digital learning object about breast cancer, using adapted questionnaire ${ }^{[10]}$. The collection period occurred in April 2011.

The group members were invited to participate in the study in the form of computer workshop, which had the opportunity to learn to use basic functions of the PC and the Internet, by appropriating the technology that would serve as the basis for the next phase. At the first meeting addressed the use of computers and their operation, data storage, using the program Microsoft Paint 2007® in order to train skills with the mouse and keyboard, in addition to producing a personalized badge for use the next meetings. We sought to address issues that were close to the reality of the participants and awaken interest in computer use.

At the second meeting, and the badges are delivered leaflets produced by the participants in the previous meeting, they were conducted so that they could train in pairs or trios Internet access available in all three PCs. That day, after searching the Internet for topics of interest to participants, they were invited to write in the Microsoft ${ }^{\circledR}$ Office Word 2007 to be a gourmet recipe shared with other classmates, thus taking advantage of skills training programs for editing text.

In the third and fourth meetings was worked specifically the digital object learning about breast cancer previously structured, tailored and made available through CD-ROM, to the participants. In the instrument prepared for the evaluation, each participant was asked to indicate their opinion by means of a structured questionnaire, as standards of ISO 9126 for the items mentioned above, the degree of relevance and quality of belonging to the learning object. Each of the items listed on content (8 items), usability (6 items) and didactic (7 items), was evaluated for the degree of relevance: "completely agree", "agree", "no opinion", "disagree" and "completely disagree".

It was chosen to present the tables that follow, only the results obtained in columns of responses "agree" and "agree" to the extent that these met the specific goals of validating the content-based judgment ${ }^{[9]}$. Favorable opinions were accepted consensus with percentage greater than or equal to $50 \%$. It is also worth nothing that, as the instrument items were satisfactorily validated by the judgment of experts by descriptive analysis (frequency and percentage) was not necessary to perform statistical tests of reliability for accuracy. The quantitative data originated of the questionnaire evaluations was tabbed in Microsoft Office Excel 2007® spreadsheets, analyzed through treatment with descriptive statistic measures such as the occurrence of central tendency and frequency. To increment the quantitative data was used the analysis of qualitative data of the interview to form the constructive category ${ }^{[11]}$. The transcription of the group interview was made, and then organized and divided in parts, connecting and searching to identify trends and relevant standards; after was re-evaluated, and formed categories, considering implicit messages in the materials ${ }^{[10]}$. Connections and relations were established between the qualitative data analyzed with the quantitative data treated and with what is available on bibliography about the content.

The Project was approved by Research of UFRGS and by Research Ethics Committee of the Municipal Health Department of Porto Alegre. The members signed the Term of Informed Consent (IC) which had voluntary participation, the possibility to stop your contribution at any time and anonymity of the participants in the dissemination of results.

\section{Results}

The population of study shows average of 63 years old with variation of between 51 to 78 years old. The participation time on the group ranged from 2 to 16 years, with an average of 9 years and 11 years of mode. About their professional activities 
and knowledge about computers, most of them declared themselves as "housewives" or "retired" and 82.25\% (13 participants) answered having basic knowledge, evidencing the lay character of the most participants about computer.

With respect to evaluation of the participants about the content of the learning object about breast cancer, had the sum of the scores of agreement higher than 9.3 in all items, as shown in Figure 2. When asked about the usability, the data in Figure 3 shows that there was always the sum of the scores of agreement higher than 8.7, although a small portion have disagreed on item "has clear instructions" in item "is easy to use". On the issue of "teaching", the users showed agreement in most cases, there is the sum of the scores of at least 8.5 on all items, although few had disagreed or completely disagreed at times, as was the case of "contextualize the concepts", "identifies previous knowledge" and "identifies learning objectives" (see Figure 4).

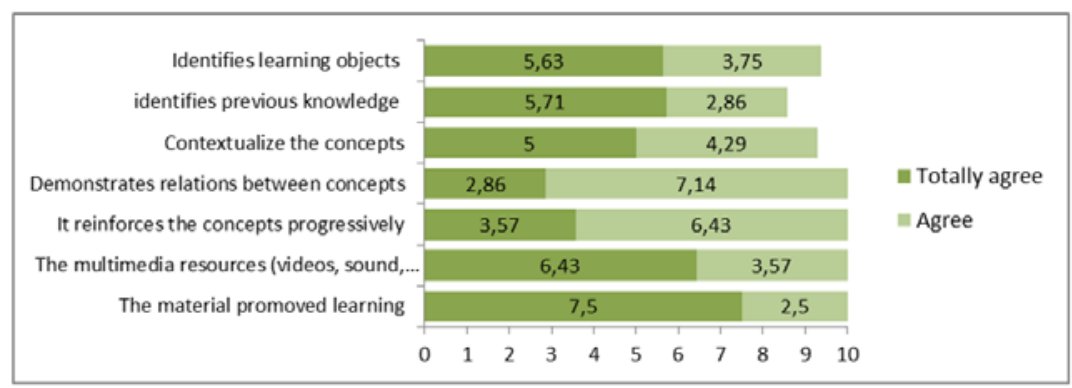

Figure 2. Scores on the assessment of contents of digital material.

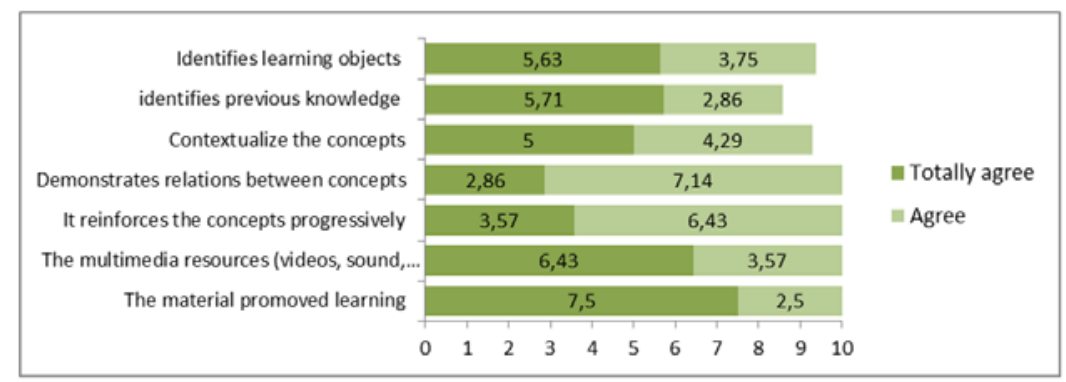

Figure 3. Scores on the evaluation of didactic of digital material

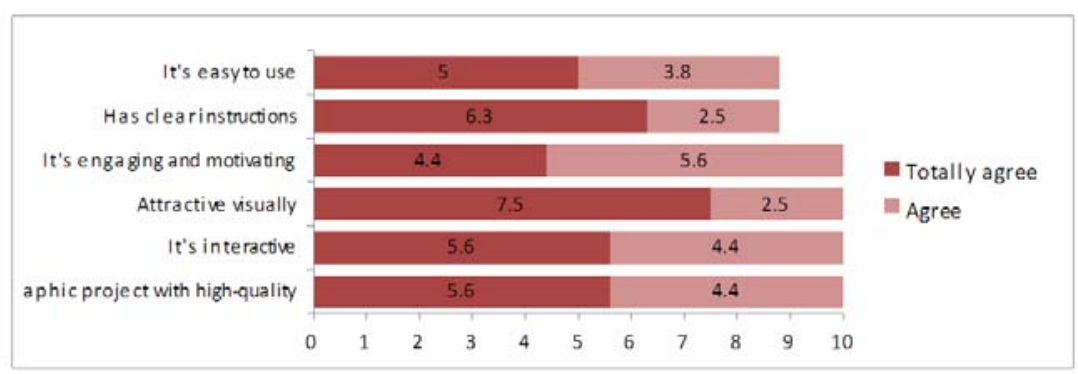

Figure 4. Scores on the evaluation of usability

From the transcript of the group interview, there were three main themes present in the speeches: use of computers, access to information and digital object learning about breast cancer. 


\subsection{Use of computers}

The participants showed interests with found out functions and utilities of computer on their daily activities, which is present in the speeches of the participants A e B:

"Look, I came here and learned how to erase the address of my friends at the time of forwarding my emails, to pass the pictures from my camera to computer [...] So I knew something, we go digging and learn, but here I took a lot of doubts, very good [... . ] "(Participant" A ").

"Oh, now I've learned that program here, I'll write a letter to everyone, I don't care, my relatives will find it very chic if I send a few different cards. I loved" (Participant "B" ).

In addition, they reported the experience of using the computer for the first time, as it brings the following statement:

"In the beginning it is difficult to use for those who don't know how to use the computer [... ] Was difficult to control the mouse, the second time I felt better, I could coordinate more "(Participant" C ").

There was also interest in continuing the activity, as noted in the speech:

"This is the last class? It couldn't finish, it would be nice if you continue this work with us. There's this a lot of computers thrown here, what a pity! Can you set up a lab here? "(Participant" B ").

The suggestion by one of the participants that she had hoped the course would continue, could be explored more fully in terms of lessons learned and suggestions for the use of digital learning objects in other health promotion activities.

\subsection{Access to information}

The participants showed interest and understanding in relation to the computer as a mean of communication and the Internet as a source of knowledge, as it brings the speech of the participants:

"This information is not available in time accessible to people, with the material we have time to read, to learn better [... ] "(Participant" E ");

"This material showed the breast from the inside, it was cool, because these things aren't like TV, only show the picture on the outside, not here, we can see inside, so one understands this better than just talking [... ] "(Participant" D ").

\subsection{Digital object learning about breast cancer}

With regard to the digital object of learning about breast cancer, participants were satisfied as mentioned that.

"It was easy to use, I like it" (Participant "E")

"I found the language accessible the language, this is important "(Participant" A ")

"There's too much information, I learned a lot "(Participant" C ").

Some aspects were highlighted by the users, especially in relation to instructions, for example:

"The initial part of the material could be clearer, so, for people who don't know where to start, impairs a little "(Participant B). 
Although specifically about the digital material, the participants pointed out the topic of breast self-examination as prominent as it brought:

"The self-examination was wonderful, had things I didn't know, it was easy to understand, it goes up under the arm, I didn't know [... ] "(Participant" F ")

"You see, and we don't do this right!? Looseness, you see, isn't difficult, we just have to move and don't cost a thing, it is a lack of habit, right! " (Participant" D ").

Could notice that the material generated interest among the women of climacteric, when they brought to discuss personal issues and experiences regarding family and acquaintances, reporting that they would like to present the object to them, the example of what the participant says:

"We can take the $C D$, right? I'll show my friend, her sister had breast cancer, but took the breast, it's everything alright now, but even so, I'll take her to see [...] "(Participant" A ").

Also questioned whether the activity conducted in workshop form couldn't be repeated in other establishments, such as the participant says briefly:

"This work is very good, could go to other health centers, I'm upset it's over, I was thinking that we were going to have more classes [... ] "(Participant" B ").

\section{Discussion}

The participants are an older population and lay on the subject breast cancer and use of the computer, making it necessary to adapt the activities with a basic training to insert themselves in the context of the proposed technology for use during the study, before presenting them the object of digital learning about breast cancer. To apply the object, also was necessary a lot of informatics tools, which was a barrier for the researchers, because the health centers not always have computers for so much people. They were satisfied with the material as the sum of the scores of agreement was always above 8.5 for all items.

About the evaluation of the content of digital material, all the scores were higher than 9.0. It's important observe the items "clear and concise" and "relevant", because in this kind of material is easy to get out of the main target, and put information that isn't so relevant to your population. The informatics gives us the chance to approach a lot of issues, but we learned that more important than the quantity of topics is the quality and the relevant things that would really be used by the participants, noted on the item "Includes appropriate quantity of material”, with score of agreement at 10,0. It is observed about the content material provided relevant knowledge and helped to develop cognitive skills on the subject breast cancer, with emphasis on self-examination on video. This way, it is believed that the content of learning in small groups or blocks assists in making learning more attractive and interactive ${ }^{[12]}$.

About the usability evaluation of users for the items "visually appealing", "high-quality graphic design" and "is interactive" the questionnaire, showed that multimedia features were effective, this shows how important is to create a material for a target group The materials for groups normally are too rare, and this kind of material involves creativity, interactivity and is more interesting than the usual groups, even with the same content, in this case, breast cancer. The items "has clear instructions" and "is easy to use" obtained a lower degree of agreement and may be correlated with the suggestions of the participants presented the reports of the group interview, according to the opinions of the users, it was understood that the instructions and buttons should be appropriate to better serve the public it is intended. It is understood that the assessment item on the ease of use can also be related to lack of familiarity with the subject of the proposed technology. 
On the issue of didactic is possible to verify that the use of technology studies to transform existing data into information from the benefits of information technology (IT) in health can be a possible alternative to the nurse and tells literature9, for the evaluation of participants. However the items "presents concepts in context," "identifies knowledge" and "identifies learning objectives" suggest areas for improvement and adaptation to the lay public, highlighting the possibility that the learning object has which is to update it and reuse it in other context ${ }^{[13]}$. The learning that this material promoted is evidenced by the item score $(10,0)$ and also for the speeches. This kind of material can be an attractive option to talk about various issues, and promote knowledge and in consequence self-care, health promotion.

From the reports, the participants revealed that they could overcome the limits and challenge themselves by acquiring skills related to IT during the proposed activities, providing new and real prospects for their future as evidenced already by other authors in your studies ${ }^{[8]}$. They were interested in finding functions and uses of computer and continue the activity. They saw the computer as a means of communication and the internet as source of knowledge, presenting enjoyment with the activity and digital material. Could correlate the contents of the object with the family context, with emphasis on breast self-examination. The participants contributed with suggestions about the instructions of the material. The activity in group made possible the inclusion, appreciation and identification between the participants ${ }^{[14]}$. The dynamic permitted that the participants could identify their difficulties and support each other to learn, also there was promotion of selfesteem.

In addition, this study showed that the caregivers need to be trained in the use of digital learning objectives. The participants say about the impact of the material with respect to potential lifestyle changes, like self breast examination more regular, the change in dietary habits, and a keenness to share learning with others. However, one must consider the context in which they live and the alternatives to the use of computer and Internet to access and information.

\section{Final considerations}

The proposed objectives were achieved, demonstrating the satisfaction of users with digital material and provided with new learning, this can be a useful tool to be used by nurses in health promotion. It is believed that the "digital inclusion" has become possible and that group was important to the effort. With this study, we can use technology not previously explored and underutilized spaces in the field of study, which increases self-esteem and self-image of participants. Therefore, it is suggested to the Health Center the use of his computer lab for the benefit of their community. It is expected that projects like this can continue and lead to new discoveries related to health education with computer support and encourage the use of the tool by health professionals in primary health.

Therefore, from the results obtained, we can evaluate digital learning object about breast cancer in the context of their own core network users relative to content, usability and didactic material, approaching the subject of informatics' breast cancer from the use of digital material by the group of climacteric women and his account. With the data from the questionnaire, augmented by reports, it was found that addressed the issue with the chosen didactic (PBL in digital learning object) and applied to users of primary care network, has attracted the interest of women and changed their perspective on computing, promoting changes in self-esteem of these women from learning the computer. Finally, we observe that although the process of implementation of innovative practices such as the use of digital learning object, requiring adjustment period with the audience the proposed technology, so they can be inserted in health education and produce effects not only in relation to the theme you want, but also the social context of the users. They must be encouraged and supported initiatives that challenge patients and professionals to become health education in primary care more attractive and current.

\section{Acknowledgement}

Special thanks to the team of Virtual Teaching Laboratory - Nursing (Levi-Enf) of Federal University of Rio Grande do Sul for their efforts to adapt the digital object learning about breast cancer to the reality of users of primary healthcare 
professionals and users and the Health Center IAPI and Climacteric Group for providing their space and contribute to the development and implementation of this study

\section{References}

[1] Brasil. Ministério da Saúde. Portaria 399/GM de 22 de fevereiro de 2006: Divulga o Pacto pela Saúde 2006 - Consolidação do SUS e aprova as Diretrizes Operacionais do Referido Pacto. Ministério da Saúde, 2006.

[2] Brasil. Ministério da Saúde. Instituto Nacional de Câncer (INCA). Estimativa 2010: incidência de câncer no Brasil / Instituto Nacional de Câncer. INCA, 2009.

[3] Brasil. Ministério da Saúde. Instituto Nacional de Câncer (INCA). Câncer de Mama: INCA, 2010a. Available from: http://www.inca.gov.br/conteudo_view.asp?ID=336.

[4] Brasil. Ministério da Saúde. Secretaria Nacional de Atenção À Saúde (SNAS). Instituto Nacional de Câncer (INCA). Controle do Câncer de Mama - Documento de Consenso: INCA e Conselho de Preveção e Vigilância (CONPREV), 2004.

[5] Brasil. Ministério da Saúde. Climatério: Ministério da Saúde, 2010b. Available from: http://portal.saude.gov.br/portal/saude/visualizar_texto.cfm?idtxt=33924\&janela=1.

[6] Coscarelli, C. Objetos para aprender fazendo: Universia, 2004. http://www.universia.com.br/html/materia/materia_dacf.html.

[7] Hannah K J, Ball M J, Edwards M J A. Introdução à informática em enfermagem. Ed. Artmed: 2009, 388p.

[8] Mosqueira J J M, Stobäus C D, Ferreira A J. Oficinas de Inclusão Digital para Idosos: aprendizado de novos conceitos de envelhecimento. In: Terra N,. et al. Envelhecimento e suas Múltiplas Áreas do Conhecimento. Ed. EDIPUCRS: 2010, 109-117.

[9] Polit D F, Beck C T, Hungler B P. Fundamentos da pesquisa em enfermagem: métodos, avaliação e utilização. EdArtmed: 2004, $487 \mathrm{p}$.

[10] Tarouco L M R. Avaliação de objetos de aprendizagem. Centro Interdisciplinar de Novas Tecnologias na Educação (CINTED): 2004. Available from: http://penta2.ufrgs.br/edu/objetosaprendizagem/sld001.htm.

[11] Lüdke M, André M E D A. Pesquisa em educação: abordagens qualitativas. Ed EPU: 1986, 99p.

[12] Cavalcante M T L, Vasconcellos M M. Tecnologia de Informação para a Educação na Saúde: duas revisões e uma proposta. Ciênc. Saúde Coletiva. 2007; 12: 611-622. http://dx.doi.org/10.1590/S1413-81232007000300011

[13] Tarouco L M R, Fabre M C J M, Tamusiunas F R. Reusabilidade de objetos educacionais. RENOTE - Revista de Novas Tecnologias na Educação. 2003; 1: 1-11.

[14] MAFFACCIOLLI, R.; LOPES, M.J.M. Educação em saúde: a orientação alimentar através de atividades de grupo. Acta Paul. Enferm. 2005; 18(4): 439-445. http://dx.doi.org/10.1590/S0103-21002005000400014 